\title{
EDUCAÇÃO MORAL: ADESTRAMENTO OU REFLEXÃO COMUNICATIVA?
}

\author{
Pedro Goergen *
}

\begin{abstract}
RESU M 0: 0 texto busca elucidar al guns dos mais relevantes aspectos da educação moral no contexto do mundo plural contemporâneo. Parte-se do suposto de quea educação moral épossível enecessária, mesmo no cenário atual de desestabilização dos valores fixos e universais da tradição. Esta educação moral, portanto, já não pode ser concebida como transmissão de valores e comportamentos morais, mas como a introdução dos educandos no mundo conflitante das concepções morais, objetivando consensos mínimos que sirvam de base para o seu agir moral. Por meio de uma relação pedagógica reflexivo/comunicativa espera-se sensibilizar os alunos para a problemática da moralidade, bem como promover a estruturação de uma subjetividade a partir da qual cada um possa tomar suas decisões morais com responsabilidade.
\end{abstract}

Palavras-chave: Educação moral; Ética; Valores; Subjetividade; Pluralidade.

\section{Introdução}

As considerações a seguir não buscam oferecer indicações a respeito de valores e procedimentos morais, cuja transmissão a escola ou os professores deveriam assumir. 0 entendimento da educação moral como transmissão de virtudes, que da tradição nos é familiar, está hoje ultrapassada. Educação moral, no ambiente escolar, significa introduzir os educandos no contexto do debate ético com o objetivo de fomentar, por meio de um procedimento argumentativo/dialógico, a sensibilidade para as questões morais e a formação de uma subjetividade como o fórum de decisões práticas.

0 presente artigo apresenta-se na forma de um ensaio, no qual são defendidas algumas posições relativas à educação moral que me pa-

Professor titular da Faculdade de Educação da Unicamp. E-mail: goergen@unicamp.br 
recem relevantes nestes tempos de pluralidade em que vivemos. Trata-se da sistematização provisória de alguns pontos de vista que pretendo desenvolver de forma mais sistemática e consistente num momento futuro, no âmbito de um trabalho mais amplo. Esta limitação explica o ar ligeiro do texto e sua sumária sinalização bibliográfica, precariedades estas que o leitor perceberá imediatamente. Trata-se apenas de desenhar a nervura de um argumento a respeito da educação moral que a) defende a possibilidade e a necessidade da educação moral de crianças e jovens; b) abandona a versão tradicional de caráter instrumental, centralizada na transmissão de comportamentos virtuosos com base em ideais pré estabelecidos e c) insiste na plausibilidade de uma educação moral de corte argumentativo/comunicativo.

Considerando o caráter ainda provisório do texto, estes temas ainda não se encontram desenvolvidos com a devida sistematicidade e profundidade. M esmo assim, espero que as reflexões que apresento sirvam como introdução a uma temática - a educação moral - que é, sem dúvida, de grande atualidade e urgência. No contexto escolar, o assunto obteve nova visibilidade a partir da discussão dos temas transversais. O s textos legais e a celeuma que geraram mais escondem que revelam as dificuldades de natureza teórica que subjazem à questão da educação moral. M eu propósito limita-se à tentativa de desvendar algumas dessas dificuldades, sem ainda poder oferecer uma visão mais abrangente e aprofundada do estado da questão. Para tanto, seria necessário apresentar e confrontar as teses centrais das principais teorias éticas atualmente em destaque, o que ultrapassaria em muito as pretensões do presente texto.

\section{A dissolução da conectividade entre valores eeducação moral}

0 tema da ética tornou-se central na reflexão pedagógica da atualidade. 0 grande número de publicações que, em nível internacional, ${ }^{1}$ vem aparecendo, dá um claro testemunho disso. A atenção dispensada à ética não decorre de algum modismo teórico, mas da preocupação com problemas sociais, ecológicos e comportamentais muito concretos que se originam, de um lado, do enorme poder de intervenção científicotecnológico e, de outro, da desestabilização dos valores tradicionais que serviam de orientação para a relação dos homens com a natureza e dos homens entre si. Esta preocupação está presente nos mais diferentes âmbitos da vida, inclusive no quotidiano do trabalho pedagógico, referente à formação moral dos alunos. Tradicionalmente, no contexto de valores e formas de comportamento consensualmente aceitos e social- 
mente legitimados, admitia-se naturalmente que a escola e os professores assumissem a transmissão desses valores às novas gerações. Com a crise dos valores tradicionais no novo ambiente de uma sociedade secularizada, a tradicional legitimação da formação moral instrumental caiu sob grave suspeita. No dizer de Beutler,

aqui já se coloca a pergunta a respeito do quedeve ser estimulado. Aqueles que setornam pedagogicamenteativos podem ter representações muito diferenciadas do que devem promover junto aos seus educandos, ou seja, como sua personalidade deve ser dimensionada. O s pedagogos estão longedeum consenso a respeito do que deve ser alcançado. D isso resultado o problema da colocação denormasna educação ou a perguntaa respeito dosobjetivos educacionais. (1996, p. 269)

Q uestiona-se não apenas quais valores ou formas de comportamento devem ser estimulados pela escola, mas também se cabe ou não à escola assumir tal encargo. Encontramo-nos diante de um problema que não pode ser por mais tempo postergado e nem resolvido à moda antiga.

0 que se pretende a seguir não é oferecer um modelo de "ética pedagógica" em termos de indicação de valores e procedimentos morais que deveriam ser transmitidos aos alunos, mas apresentar uma análise das dificuldades e problemas que a temática envolve. $\mathrm{N}$ ão se trata apenas de sublinhar as rupturas que a tradição vem sofrendo, mas de dimensionar 0 entendimento de uma nova realidade que 0 desenvolvimento social, científico-tecnológico e teórico contemporâneos vem instituindo. D essa nova compreensão não é possível deduzir, diretamente, novas prescrições normativas que venham substituir aquelas que perderam a sua legitimidade. Ao contrário, em decorrência da desestabilização, valores e expectativas de comportamento perdem, e ao que parece cada vez mais, a sua conectividade, a sua força vinculante.

$\mathrm{N}$ ão se trata de uma ruptura entre educação e moralidade, mas de um novo acesso a esta problemática que se distancia do preestabelecido e das exigências da adaptividade, aproximando-se da contextualidade e da reflexibilidade. A linguagem pedagógica perdeu sua univocidade e suas relações seguras, devendo arranjar-se no contexto de um mundo instável e relativo. A questão que se coloca é o que significa moral em contextos multisignificativos e plurais. ${ }^{2} \mathrm{E}$, mais do que isso, quais são os fundamentos que legitimam uma ação pedagógica que objetive a introdução de estudantes no contexto da moralidade. $\mathrm{N}$ em mesmo é possível falar, com propriedade, de uma ética pedagó- 
gica, uma vez que em ambientes multisignificativos haverá, por certo, variados e mesmo contraditórios projetos que não se reduzem a um único paradigma. Isso representa uma mudança significativa com relação à tradição que, pelo menos até W ittgenstein, ${ }^{3}$ fundava-se na perspectiva de uma única posição válida, em termos de reflexão ética e filosofia prática.

$\mathrm{N}$ a perspectiva tradicional, o esforço reflexivo em torno da problemática ética consagrava-se ao desvendamento desta verdade que, uma vez descoberta e definida, representava o polo orientador para a ação e 0 comportamento humanos. Segundo Benner,

enquanto a pergunta a respeito da eticidadee do sentido da ação humana ficar limitadaà questão da apropriação denormas reconhecidas por todos, apenaso "como" da internalização pode ser problemático. U ma vez que o "o quê" da eticidade e do sentido já estão preestabelecidos, a pergunta acerca da ensinabilidade da virtude é exterior ao questionamento da própria virtude. $(1973$, p. 17)

A virtude que, nestes termos, era considerada externa ao próprio sujeito, passa hoje por um processo de subjetivação, tornando o próprio processo formativo fator constitutivo do que pode ser entendido por virtude. $\mathrm{N}$ a perspectiva tradicional, tratava-se uma verdade única e universal que o ser humano devia internalizar e assumir como orientação de sua vida prática. Este princípio e expectativas eram também determinantes também para as discussões no campo educativo e seus objetivos, particularmente no referente à educação moral.

As discussões filosóficas mais recentes ${ }^{4}$ mostram, ao contrário, quão variados são os caminhos de acesso aos temas da ética e quanto é inútil esperar que se chegue a uma grande, universal e conclusiva teoria. ${ }^{5}$ Este debate que está em pleno andamento (Apel, Rawls, $\mathrm{H}$ öffe, $\mathrm{H}$ abermas, Rorty, Tugenhat) já tem como certeza preliminar 0 abandono definitivo da verdade ética única e universal, seja ela de natureza metafísica ou teológica. Trata-se da dissolução do chamado 'círculo prático', ou seja, daquela relação entre a norma ou o valor consensualmente aceitos e a necessidade de sua realização prática. Contudo, mesmo consciente dessa ruptura, o debate contemporâneo não abandona os principais temas e desidérios da teoria ética tradicional. Abandonam-se as expectativas de uma teoria única e universal, mas persistem as dificuldades teóricas e a busca de fundamentação (O liveira, 1995, p. 9). D iferentemente do que muitas vozes cheias de nostalgia lamentam, a perda das certezas tradicionais ou pelo menos das expectativas 
de certezas que orientavam o esforço ético não deve ser entendida apenas como um déficit, mas como um ganho. Se, de um lado, há a irreparável perda de segurança e a desestabilização que isso significa, constata-se, de outro, uma aproximação à real condição humana que é sempre precária e antinômica. $\mathrm{N}$ este sentido, o despojamento das certezas éticas tradicionais insere-se perfeitamente no processo moderno de secularização que se limita exclusivamente àquilo que é apenas humano.

A recente retomada do debate ético e o conseqüente retorno do tema da ética, que foi central na tradição filosófico/educacional, não significam que se possa dar conta desse novo encargo por meio do recurso aos mesmos métodos que foram usados por R ousseau, Pestal ozzi ou Froebel. Vale dizer que o novo interesse pelo tema da ética não representa uma vitória da tradição, uma vez que não é possível tratar este tema com os mesmos recursos mentais do passado. 0 horizonte das questões éticas tradicionais deve ser reapropriado, mas com a diferença de que isso não é mais possível com os mesmos recursos teóricos e nem na perspectiva das seguranças então aceitas. 0 vazio aberto entre a persistência da preocupação ética e 0 abandono das abordagens tradicionais precisa ser preenchido novamente com reflexões que decorrem do transformado ambiente contemporâneo. ${ }^{7} \mathrm{~N}$ ão se trata da elaboração de um novo cânon de valores e expectativas capazes de orientar a prática pedagógica, mas da aproximação reflexiva ao problema, seus paradoxos e perspectivas.

A crise de legitimidade, que reatualiza a preocupação ética, representa uma nova chance de romper com as representacõos estáticas do passado e abrir espaço para novas reflexões que estabelecem a relação com a realidade da sociedade contemporânea. Se a educação hoje é considerada como um problema moral, isto é conseqüência da crise de legitimidade que, ao mesmo tempo, oferece a chance de romper com os rígidos campos de significados e abrir espaços para novas reflexões, as quais estabelecem relação com a problemática da sociedade contemporânea. As fundamentações clássicas da educação, com auxílio de imagens humanas de caráter religioso ou especulações antropológicas a respeito de uma natureza humana única, não parecem ser mais suficientes porque não resistem aos princípios teóricos diferenciados, mas sobretudo porque subestimam a educação (0 elkers, 1992, p. 11). N esse sentido, qualquer teoria que se proponha oferecer uma explicação ou uma proposta unitária para a questão da ética está condenada a envolver-se rapidamente em crises de identidade. 


\section{Aprender a lidar com incertezas}

0 discurso dos bons tempos é uma forma de crítica nostálgica das circunstâncias multisignificativas da realidade educacional e da moralidade contemporâneas. No entanto, o contexto plural é hoje uma realidade e de pouco adianta chorar os cânones perdidos ou sonhar com novas tábuas de lei, talhadas em pedra; é mister discutir os problemas, os paradoxos e as perspectivas de uma nova ética pedagógica adequada aos novos tempos que, queiramos ou não, são tempos plurais. No campo da educação moral, a questão não é mais como transmitir aos alunos um determinado conjunto de normas e valores que, no passado, eram deduzidos dos axiomas básicos de teorias éticas gerais que se afirmavam superiores a todas as outras. Segundo 0 elkers, "uma falha central da tradição pedagógica foi a representação de relações estáticas, portanto, relações de tipo linear e não diferenciado; só assim a idéia da derivação do particular, a partir do geral, podia parecer possível e plausível." (1992, p. 13).

Em nenhuma de suas dimensões e, por conseguinte, também não no da ética, a educação é o espaço de implementação autoritária de verdades, normas ou expectativas. E a razão é simples: vivemos numa época em que os princípios e valores de caráter a-histórico/transcendental da tradição metafísico/teológica perderam seu poder de conviç̧ão, abrindo espaço para o histórico, o precário, o contexto. Esta nova circunstância foi muito bem percebida por Paulo Freire, inclusive em sua dimensão política: "Só existe saber na invenção, na reinvenção, na busca inquieta, impaciente, permanente, que os homens fazem no mundo, com o mundo e com os outros." (1975, p. 66). O espaço da educação é a práxis falível que se define pelo sucesso ou pela frustração. $E$ até mesmo estes conceitos são relativos, uma vez que o seu teor, isto é, o que significa sucesso ou insucesso é objeto de permanentes discordâncias, sendo constantemente revistos e redefinidos, segundo os pontos de vista a partir dos quais são estabelecidos. D essa forma, é preciso aprender a lidar com incertezas. A aprendizagem tem um sentido de preparação para a ação concreta que não é uma transcrição mecânica de valores, ou normas ge rais, mas decisões circunstanciadas.

0 correto agir é o resultado de um projeto de aprendizagem, uma tarefa educativa. 0 correto agir não preexiste na forma de prescrições que a educação teria como que em carteira para transferir aos alunos. A educação, portanto, não pode gerar nos alunos um conjunto acabado de disposições (virtudes) voltadas para a justiça, para o respeito ou a soli- 
dariedade. Em outros termos, não é pela educação que alguém se torna justo. 0 que a educação pode fazer é abrir aos alunos o mundo do agir moral por meio de um processo pedagógico/reflexivo/comunicativo a respeito das proposições morais que integram 0 ambiente cultural. M esmo assim, a introdução do aluno no mundo moral e sua familiarização com as expectativas de comportamento (normas) culturalmente estabelecidas não significam que ele de fato irá comportar-se em conformidade com isso. Há uma diferença entre este cosmo moral e o comportamento concreto. Este a escola não tem como garantir. A ação e o comportamento concretos realizam-se no contexto de múltiplas circunstâncias e determinações, as quais resignificam constantemente os princípios morais gerais. As crianças podem ser introduzidas no mundo moral, mas seu comportamento não pode ser predefinido.

Contudo, se moral não é a aplicação de leis universais acima de qualquer circunstancialidade, também não é apenas a soma de convenções ou mesmo comportamentos ad hoc, totalmente imersos no circunstancial. M oral são regras precárias, configuradas concretamente no interior de um mundo de circunstâncias, mas à luz de princípios éticos mais gerais. Estes princípios ou normas não especificam no detal he as condições de sua validade e observância, mas insinuam a necessidade de uma aprendizagem de como, em determinadas circunstâncias, estes princípios devem ser vividos ou mesmo justificadamente transgredidos. ${ }^{8}$

A educação moral não serve para internalizar normas corretas, mas para aprender que as normas são necessárias como parâmetros de salvaguarda de princípios mínimos de convivência humana, como o respeito à vida, a dignidade do indivíduo, o respeito ao meio ambiente, e para aprender a lidar com estes princípios em circunstâncias concretas. N ão existe uma 'economia' moral definitiva, ou seja, um equilíbrio ideal entre normas e sua aplicação concreta que possa ser esterilizado do contágio da circunstancialidade e tornar-se fixo, aplicável tout court em qualquer experiência subsequente. "N ormas e princípios morais são prescrições frágeis que permanentemente oferecem oportunidade para a educação" (O elkers, 1992, p. 14).

Educação moral, portanto, não pode ser interpretada como uma internalização mecânica ou literal de normas. Educação moral é muito mais um processo de familiarização com um discurso moral a partir de princípios gerais, na sua interface com circunstâncias concretas. N ão compete, portanto, à educação assumir um controle do mundo moral; sua tarefa restringe-se à introdução do educando no contexto dos princípios morais e nos modelos de debate, sendo que ela não dispõe de recur- 
sos ou mesmo de autoridade para impor determinadas formas de comportamento, livres de desvios.

Com isso, o acento setransfereda perguntaarespeito do "como" da internalização danorma para a perguntaacerca do "quê" da eticidade, ea perguntaa respeito do "como" da internalização não se coloca mais como pergunta a respeito da apropriação de formas preestabelecidas e tradicionais de vida, mas como a pergunta a respeito do "como" da organização de uma educação que, antes de tudo, deve ainda determinar o seu sentido. (Benner, 1993, 18)

Isto, que pode parecer banal, na verdade, assume grande importância, tendo em vista o uso moralizante que certos grupos pretendem fazer da escola para impor seus interesses como, por exemplo, a família que, desejosa de ver seus filhos assumindo determinados comportamentos, exige que a escola trate de enquadrar seus pupilos rebeldes, tornando-os comportados, ou seja, conformes às suas expectativas de comportamento.

A moral sempre preserva um caráter de ambivalência, fragilidade e risco e, portanto, é al go que deve ser cultivado. Esta é a razão da educação moral. A educação moral assenta sobre uma comunicação difícil que implica, inclusive, a legitimação de normas ou regras (gerais) que se oferecem ou são propostas como modelo de comportamento. É a partir desta fundamentação ou legitimação das normas que se justifica o processo de aprendizagem. U ma certa imposição das normas (como superiores) só é admissível no início do processo educativo se ele não quiser incorrer em doutrinação. É claro que a educação moral deve preencher positivamente seu espaço, mas os objetivos que serão de fato alcançados não podem ser fixados no interior desse espaço educativo. Este é o paradoxo do qual nenhuma educação moral pode esquivar-se: os efeitos de vem ser de alguma forma calculados, mas este cálculo não passa de expectativa. 0 agir educativo encontra-se sempre sob o signo da contingência, tanto no que se refere às intenções pedagógicas, quanto no que diz respeito aos seus efeitos. Educação moral, portanto, não significa a incorporação de preceitos e normas que são impostas a partir de fora como absolutas, mas aprender a lidar com as incertezas, com as precariedades, as contextualidades e os paradoxos das situações concretas à luz de alguns princípios gerais mínimos.

As crianças não nascem boas nem más. Tanto a teoria de Rousseau do bom sauvage, quanto a crença no pecado original são mitos sem importância para 0 trabalho pedagógico. Estas teorias desfocalizam o olhar pedagógico, uma vez que, segundo a convicção de Rousseau, a educação 
moral é desnecessária já que ela haveria de desenvolver-se naturalmente a partir do interior da criança, se esta for devidamente protegida ${ }^{9}$ das influências maléficas da sociedade e, na visão religiosa, a moral é dramatizada sob a pressão de reprimir o pecado. A questão da educação moral não trata do homem definitivamente bom, nem da internalização da única moral correta. 0 tema da educação moral é simplesmente o de como as crianças ou jovens aprendem o tratamento das exigências morais e das normas que são, simultaneamente, imprescindíveis e difíceis. Pode ser verdade, como queria Rousseau, que a vida da criança tenha 0 seu sentido em si, ${ }^{10}$ mas seu sentido emerge sempre da interação com 0 meio, o que significa que o sentido sempre traz consigo a dimensão do instável. A educação moral, entendida como comunicação moral, significa familiarizar as crianças com as dificuldades da moral, sem cujo reconhecimento o sentido do humano não é nem problema, nem uma possibilidade de vida.

Por isso, a tolerância tornou-se uma importante máxima ética, uma exigência-chave de todas as visões de futuro numa sociedade multicultural e multinacional. Uma sociedade que oferece apenas uma frágil visão de conjunto. É precisamente isso que torna mais necessária a educação, pois agora se colocam frente a frente regras complexas e emocionalmente contraditórias, que somente encontram seu equilíbrio através do exercício da tolerância. 0 s preceitos são formulados no espaço tensional entre a certeza e a contingência. A falta de certeza é uma realidade que tem de ser assumida pela educação. Aliás, como foi dito acima, esta incerteza e falibilidade são, de um lado, condição da educação e, de outro, o potencial da educação. Se existissem princípios absolutos não careceríamos de educação: eles deveriam simplesmente ser aceitos e observados. Só a incerteza e a contingência necessitam de educação. A educação serve à necessidade de aprender e não está propriamente em função dos resultados que nunca são homogêneos. N as palavras de Garz,

desenvolvimento humano, desenvolvimento para a moralidade supõe uma interação entreo indivíduo eo mundo, bem como entre o mundo eo indivíduo que leva a um intercâmbio ao longo de todo a vida. A propriação do mundo etransformação do mundo fundamentam uma história dialeticamente intrincada quesó finda com a morte- uma "never ending story". (1998, p. 13)

A teoria ética clássica sempre formulou uma relação ideal entre os objetivos e os meios otimizados de sua concretização. Com isso, o mundo da experiência tornava-se estático e enrijecido. $\mathrm{H}$ oje, sabemos que 0 mundo educativo não pode ser rigidamente controlado segundo um 
plano preestabelecido. A mecânica tradicional baseava-se num mundo homogêneo e bastante estável que assegurava a realização de seqüências imagináveis, que desembocavam na conquista de certos objetivos, previamente fixados. A metáfora do espaço e da ascensão em direção à luz usada por Platão ${ }^{11}$ influenciou toda a literatura educativa. Segundo esta imagem, os procedimentos educativos não eram entendidos como um processo. Entender a práxis educativa como um processo é entendêla como uma ação que se realiza, sim, à luz de objetivos e ideais, mas que não são fixos como não são fixos os caminhos que a eles devem conduzir. 0 idealismo platônico carece de uma leitura historicizada, na qual os ideais, as utopias, mais que pontos fixos, são expectativas historicamente estabelecidas e dial ogicamente validadas, portanto, sujeitas a permanentes redefinições, sempre provisórias. A imagem ideal apenas estimula as expectativas, mas não descreve o verdadeiro processo educativo. É preciso distinguir entre as necessárias utopias que embasam as expectativas ge rais e a realidade educativa. Tal como a reflexão pedagógica em geral, também a reflexão moral incorpora idealidades que, insistentemente, afirmam sua plausibilidade contra as permanentes frustrações e reveses que the são impostos pelas contigências e circunstancialidades, não raro paradoxais, da realidade. As utopias sociais podem e devem ser vistas como o que de fato são: expectativas do espaço público que, embora cientes de seu caráter utópico, não podem deixar de ser formuladas.

Precisamos entender que a educação não é apenas um agir técnico que, pela implementação de determinados procedimentos, realiza objetivos preliminarmente estabelecidos. Educar-se no contexto de um mundo de incertezas, contingências e ambientes plurais, mais do que incorporar valores e comportamentos preestabelecidos, significa aprender a lidar com incertezas. A capacidade de gerenciar conflitos torna-se uma das tarefas centrais da educação moral. Com este conceito entendese não apenas a administração de conflitos, mas ação positiva sobre o chão das relações conflituais. 0 conflito é parte positiva da estratégia da práxis humana. É, inclusive, na perspectiva desses conflitos e contradições, ine rentes à própria realidade, que se abre a possibilidade da construção de um novo telos para o indivíduo e para sociedade humana.

\section{3. À busca defundamentos mínimos}

I manência e caráter histórico dos objetivos no novo cenário de incertezas, precariedades e paradoxos, caracterizam a educação contemporânea e particularmente a educação moral. A desestabilização do ab- 
soluto representa a passagem da univocidade do ideal para a pluralidade dos valores. Do ponto de vista clássico, segundo o qual o processo educativo significava a 'conformação' das crianças e jovens ao bem preestabelecido, o pluralismo moderno é paradoxal e até mesmo pósmoral. ${ }^{12}$ D o sentido transcendente, ao qual todos tinham de se adaptar, chega-se ao sentido negociado no interior do processo educativo. Este espaço educativo torna-se ele mesmo instituidor de sentidos. $\mathrm{N}$ isso se resume a grande dificuldade da educação ética nos dias atuais. ${ }^{13}$

A relação entre 0 homem e o mundo era entendida pela educação tradicional como uma relação estável, sem previsão de grandes transformações. A dinâmica das mudanças, que hoje nos é tão dilematicamente familiar, não fazia parte do horizonte das preocupações pedagógicas daquela época. 0 processo de secularização dos valores tradicionais, a racionalização de todas as dimensões da vida e das visões de mundo relativizaram 0 absoluto como ponto arquimédico transcendente e comum a todos, trazendo a temática dos valores para o âmbito da responsabilidade individual. A dissolução da relação unidimensional entre 0 homem e o mundo transferiu o momento fundante das prerrogativas morais para o interior dos sistemas sociais, onde, por convenção, se estabelece o que é bom ou mau. A educação que correspondente a este novo contexto dessacralizado tem como pedra de toque a razão, que se torna responsável pela reflexão pedagógica, na qual se estabelecem os sentidos e limites do viver. 0 humano não mais emerge de um esforço adaptativo a parâmetros preestabelecidos, mas nasce de um gesto criativo. H á que estabelecer por meio da reflexão dialógica conflituosa o que é, circunstancialmente, o ideal humano e quais são as formas mais adequadas de realizá-lo, tanto individual quanto socialmente. O ra, no contexto de uma realidade altamente diferenciada, a definição do humano resulta necessariamente plural e contraditória. Este é o grande dilema da discussão ética na contemporaneidade: como conciliar esta pluralidade sem recorrer a princípios transcendentais, de um lado, mas sem admitir 0 relativismo de todos os valores e normas morais, de outro.

M uito antes da educação, a arte e a filosofia deram-se conta dessa nova realidade. A filosofia de $\mathrm{N}$ ietzsche, ${ }^{14}$ enquanto crítica implacável dos valores tradicionais da moral unitária e universal - para o filósofo uma moral do ressentimento - é o exemplo paradigmático. 0 pós-modernismo, que tem em $\mathrm{N}$ ietzsche suas primeiras raízes, ${ }^{15}$ tem como pressuposto básico a existência de um universo plural, ou melhor, a admissão de uma pluralidade universal. Giddens fala de uma 'contextuality of action' (1987, p. 99), Lyotard, de 'jogos de linguagem' (1983, p. 23), 
Kohlberg, de moral pós-convencional (1981, p. 423), Lipovetsky, de 'ciclo pós-moralista' (1994, p. 58). Segundo estes autores, a pluralização do mundo envolve também a pluralização da moral. Com a relativização da relação entre 0 ser humano e o mundo, também a moral estaria tornando-se plural, num universo plural. Esta visão representa o contraponto à universalidade que era peça central da filosofia kantiana. ${ }^{16} \mathrm{~N} 0$ entanto, diga-se de passagem, que um relativismo de corte mais radical não é fácil de ser defendido porque, além da contradição lógica que envolve, se conflitua com a prática humana, sempre voltada para a busca de critérios gerais (ainda que históricos e precários) de ação. ${ }^{17}$

Com a pluralização do cosmo moral, a teoria da educação entra em crise. Ela se vê na iminência de ter que abrir mão da 'grande narrativa' e render-se à práxis lingüística de grupos sociais e suas interações comunicativas. Lyotard, por exemplo, nega a possibilidade de obrigações absolutas, uma vez que tais obrigações teriam de ser expressas por meio de proposições lingüísticas, sendo que nenhuma delas pode ser considerada última, definitiva $(1985$, p. 8). Proposições definitivas como as que imaginava Kant deveriam estar dotadas de validade absoluta e, por isso, deveriam ser vazias de qualquer experiência. Como isso, é praticamente impossível, prevalece 0 'pluralismo' que dá origem ao paradoxo pedagógico que resulta da tensão entre a busca de máximas absolutizantes e a pluralidade de mundos na qual está ambientada a ação pedagógica concreta. Diante desse paradoxo entre 0 absoluto e 0 relativo, adensa-se a necessidade de um núcleo mínimo, capaz de nos por a salvo do relativismo ético que, no limite, eliminaria a possibilidade de qualquer moral vinculante através da afirmação da privacidade absoluta do cultural ou mesmo do subjetivo. N esse caso, a própria educação que visa a formação do ser humano estaria destituída de fundamento e deveria desaparecer. ${ }^{18} \mathrm{~A}$ intenção de Kant era precisamente essa de formular um fundamento universal mínimo que não estivesse vinculado a nenhuma realidade concreta. Este núcleo, assim queria Kant, deveria ser o chão comum sobre o qual poderiam ser intermediadas as realidades plurais. Esta razão prática, intermediante, não poderia, ela mesma, ser plural.

Se adotarmos o pluralismo no âmbito das expectativas de validade, das normas e princípios morais, aproximamo-nos da arbitrariedade. Kant tinha razão ao afirmar que da realidade plural não se pode avançar para a pluralidade de princípios, mas que da expectativa de validade dos princípios se pode avançar para o ordenamento da moral, embora este ordenamento não se realize concretamente. 0 fato de um princípio não ser observado na realidade não permite concluir que o princípio seja 
inválido. H öffe lembra que se os $\mathrm{D}$ ireitos $\mathrm{H}$ umanos são desrespeitados na prática isso não implica a invalidade moral destes princípios (1990, p. 135).

Os dois modelos que conduziam a prática pedagógica tradicional - a influência externa sobre o educando e o desenvolvimento natural não se sustentam. Tanto a influência externa quanto o desenvolvimento natural são movimentos que implicam uma causalidade que não leva em conta as interferências sociais e biográficas. $\mathrm{N}$ a prática, uma tal assepsia é impensável. O s novos cenários da educação moral nos contextos de pluralidade são complexos e rompem com as teorias lineares da tradição. Contudo, se no campo da educação moral estão superadas as relações lineares que não levam em conta as variáveis sociais e biográficas, isso não significa a afirmação pura e simples da pluralização dos supostos morais. Permanece a tensão entre a tese central de Kant de um suposto universal e a perspectiva posterior de uma relativização sem limites. Como foi dito, se, de um lado, foram exageradas as expectativas com relação aos efeitos cau sais da educação moral clássica, de outro, foi igualmente apressada a adesão mais recente ao pluralismo sem limites. Daquele nasce 0 absolutismo, este redunda em relativismo. $\mathrm{N}$ a verdade, trata-se de um processo de relações comunicativas que, em princípio, não têm começo nem fim. N o dizer de 0 elkers, "educação é um processo e não um produto." (1992, p. 99). Penso que é nesta linha de entendimento que podemos ver uma luz para a educação moral em meio à profunda desorientação, gerada pelo ambiente de pluralidade social e desestabilização dos valores tradicionais: qualquer projeto de formação moral - e esta parece evidenciar-se mais necessária do que nunca - exige impreterivelmente 0 estabelecimento de princípios universais mínimos que sejam vinculantes para todos.

0 grande problema que se coloca atualmente para a educação moral é a dificuldade de estabelecer um fundamento vinculante dos objetivos e ideais da moralidade. A polissemia (moral) da sociedade contemporânea, que se torna particularmente manifesta aos nossos olhos no contexto da mobilidade global, parece dar razão a $\mathrm{H}$ eidegger quando este fala de "Ab-grund", o fim de todos os fundamentos. ${ }^{19}$ A crítica ao 'ser', como o fundamento do pensar ocidental, traduz teoricamente um dos traços marcantes da cultura e da sociedade contemporâneas: o ser dissolve-se em saudade e deixa seu lugar para o ter. Esta passagem, presente na crítica de H eidegger, coloca sob suspeita todo o gesto educativo organizado a partir de um fundamento estável, considerando-o uma interferência indevida na particularidade do indivíduo, da situação, do 
momento. Este discurso particularista pós-moderno, ${ }^{20}$ na medida em que nega o fundamento de qualquer estabilidade, desautoriza o gesto educativo como um gesto político. Qualquer influência externa que busque seduzir os indivíduos para uma sociedade melhor, previamente imaginada, é tida como indevida.

$\mathrm{N}$ ão é fácil argumentar contra a relativização da formação moral da criança num momento histórico em que, dia a dia, ganha terreno a pluralidade social. No ambiente das formas plurais de vida em que vivemos, parece cada vez mais difícil encontrar consensos, até mesmo mínimos, capazes de assegurar um fundamento moral ${ }^{21}$ suficientemente legitimado que possa servir de base para uma influência moral através da educação. Trata-se, em última instância, de encontrar algo que justifique a educação moral.

A situação é manifestamente paradoxal: D e um lado, cresce a exigência de uma educação moral da infância e juventude e, de outro, ouvem-se as vozes daqueles que rejeitam a fundamentação última. "Tornase cada vez mais difícil relacionar a legitimidade das normas com alguma fonte de autoridade e de respeito. (...) Simultaneamente nunca, como hoje, se falou de ética. Em todos os campos da atividade social, em todos os tipos de discursos possíveis." (Cullen, 1999, p. 47). A educação moral parece ser, ao mesmo tempo, necessária, porque o ser humano e a sociedade necessitam de orientação moral, e ilegítima porque carece de fundamentos universais estáveis.

N o ambiente dos consensos tradicionais, fossem eles livres ou não, a educação podia pisar no chão firme dos objetivos que contavam com 0 apoio dos mais diferentes agentes do processo educativo. Com a 'relativização' das certezas teológico-metafísicas na modernidade e com a presente 'desconstrução' dos fundamentos racionais modernos, estes fundamentos da educação moral foram precarizados. ${ }^{22}$ Contudo, como muito bem observa Schaller, nem mesmo a escola que se dispuser a abandonar 0 barco do ensino moral, por lhe parecer náufrago, conseguirá evitar o envolvimento moral, porque a simples transmissão de conhecimentos sempre já implica uma finalidade que envolve a definição de valores e objetivos educacionais, inclusive morais. Apenas, o que antes era aparente agora ameaça tornar-se oculto. Como foi dito anteriormente, em paradoxal contradição com esta tendência que os pós-modernos pretendem definitiva, encontra-se a insistência generalizada sobre a necessidade e urgência de uma formação moral das novas gerações. $\mathrm{N}$ a verdade, a educação moral parece ser necessária e mesmo inevitável, uma vez que o comportamento moral faz parte do modo de ser humano. Também aquele que não quiser 
educar (moralmente) forçosamente deve tomar decisões morais, alimentando expectativas a respeito do comportamento dos outros e de si próprio. A educação moral parece ser uma realidade mesmo quando certas teorias pedagógicas se esforçam por negá-la.

Ainda assim, a formação moral na escola parece ser um tema bastante secundarizado ${ }^{23}$ por força mesmo do relativismo hoje dominante. A teoria pedagógica não é mais valorativa, sugestiva ou engajada na definição e defesa do bem. D omina a mentalidade instrumental que subsume a educação ao esquema meio-fim utilitarista, deixando à margem temas que dizem respeito ao sentido do humano, da vida, das relações sociais, da dignidade humana, da solidariedade. As teorias são empíricas, analíticas, histórico-relativas, não-formadoras de opinião. Diante desse quadro, é preciso perguntar de que maneira este tipo de educação pretende contribuir para a construção de um mundo melhor, já que o suposto primeiro de um tal projeto, a elaboração de uma utopia social, implica a avaliação, tematização e crítica da realidade atual. D e outra parte, se quisermos ir além de uma educação instrumentalizadora e estabelecer um relacionamento pedagógico formativo, no sentido humano e moral, necessariamente nos defrontaremos com a questão dos fundamentos de tal proposta.

D ecisões exigem princípios orientadores que legitimem esta ou aquela atitude em circunstâncias concretas. Chega-se, então, à grande dificuldade: de onde podem ser extraídos tais princípios se nem a tradição nem o mundo atual os fornecem de forma segura e inequívoca? Como agir no interior da heterogeneidade e da pluralidade éticas? São contextos que necessitam de interpretações e é fundamental saber qual o ponto de vista a partir do qual estas interpretações são feitas. Q ualquer realidade é sempre passível de diferentes leituras a depender dos critérios que subjazem a estas interpretações. I mporta saber se estes critérios são equival entes entre si ou não e de que perspectiva o são. Se forem equivalentes, qualquer leitura é igualmente legítima e chegamos ao relativismo. Se não forem equivalentes, alguns devem ser mais legítimos que outros. Como se estabelece isto?

Aqui chegamos a um dos mais importantes temas da atualidade: o espaço público. Sua relevância não do fato de estar na ordem do dia, mas do fato de não estar. 0 espaço público é o ambiente teórico/prático em que as leituras de mundo se encontram frente a frente e entram em debate. É um espaço em que prevalece o processo dialógico, levado a termo com base nos melhores argumentos, apresentados por participantes competentes e livres de coação. ${ }^{24}$ É 0 chão onde se fincam argumen- 
tativamente as estacas orientadoras para o comportamento dos indivíduos e dos grupos sociais. É o espaço onde podem ser acordados princípios mínimos passíveis de ser aceitos por todos e que tenham validade universal. ${ }^{25}$

A educação pode falhar, mas ela é portadora de uma responsabilidade formativa que nem sempre preocupa as outras instituições sociais como, por exemplo, a mídia. N esse sentido, a escola submete-se, ou melhor, integra o espaço público de discussão do qual participam as diferentes instâncias sociais, tais como a família, o governo, a I greja, os sindicatos, além, evidentemente, dos próprios profissionais da educação, teóricos e práticos. ${ }^{26}$ Insisto em dizer que esta integração da educação no espaço público, onde se tematiza e estabelece 0 projeto pedagógico, que é moral como um todo, é um dos traços essenciais de sua identidade. Por isso, transformar a escola numa atividade meramente instrumental, fazendo dela uma agência de adaptação das novas gerações ao modelo social vigente é por a perder uma de suas principais dimensões que é o indagar crítico acerca dos sentidos da vida individual e coletiva no contexto contemporâneo. É nesta perspectiva de uma educação que abrange o refletir crítico, no âmbito do espaço público, que se justifica a defesa persistente e intransigente da educação pública.

A metáfora que apresenta a educação como o fórum de debates parte do princípio do encontro dialógico de mundos relativos. 0 tema da moral, porém, e sobre isso gostaria de insistir, não pode ser simplesmente examinado desde 0 ponto de vista de mundos relativos. M oral não é apenas um contexto cujos princípios se pode assumir ou abandonar arbitrariamente. Este é um comportamento típico da sociedade de consumo, na qual impera a lei da vantagem, da negociação, do lucro, da conveniência. Este não parece ser o fundamento para uma teoria educacional, uma vez que ela, como foi dito acima, não pode deixar de incluir pretensões morais e, portanto, de formular obrigações de caráter vinculante, acima da pluralidade de ambientes e interesses individuais. 0 pluralismo dos contextos não implica que a educação seja vista como um mercado, no qual qualquer produto possa vir a ser negociado, segundo as conveniências. Este é um tema espinhoso que deve ser enfrentado com a honestidade, seriedade e responsabilidade que a prática pedagógica exige.

A respeito de determinados princípios e obrigações, por mais que se defendam relações educacionais simétricas, não há como negociar. Podemos tomar como exemplo o comportamento responsável, a digni- 
dade da pessoa humana, a solidariedade, o respeito ao meio ambiente como princípios que têm sentido vinculante, independente da concordância ou não de cada indivíduo. N ão há dúvida de que a cultura moral deve ser vista como uma realidade histórica que muda e que se renova, mas ela não é um objeto de mercado que, como se disse, possa ser negociado como se negociam ações na bolsa de valores, ao sabor das conjunturas e conveniências.

O s defensores radicais, tanto da posição absolutista quanto relativista, interpretam a moralidade desde uma perspectiva unívoca e linear e não reconhecem a paradoxal contradição que lhe é inerente. Os termos desse paradoxo são a negociação, de um lado, e a responsabilidade, de outro. A negociação atém-se ao aspecto formal-metodológico, a responsabilidade ao conteúdo da moral. No caso da negociação, o processo, o cenário, o contexto como ambiência discursiva tornam-se centrais em prejuízo do conteúdo da moral. 0 reconhecimento do caráter histórico-cultural da moral certamente atende a uma das tendências do mundo contemporâneo, pós-metafísico e pós-teológico, mas deixa em aberto a questão de fundo: há ou não há conteúdos morais obrigatórios, ainda que mínimos, que não podem ser negociados? Se, do ponto de vista teórico, o ambiente contemporâneo de grandes e aceleradas mudanças representa um mundo de instabilidade, tornando plausíveis as teses relativistas, a leitura que nasce da práxis é outra, pois ali encontramos a manifesta necessidade e afirmação de princípios, valores e obrigações básicos que não podem ser negociados.

É, sem dúvida, uma situação paradoxal. De um lado, sente-se o risco e a insustentabilidade da ontologia de bloco, unívoca para qualquer moral; de outro, a enorme dificuldade que a ausência de uma ontologia mínima traz para a relação pedagógica entre o ser humano e 0 mundo. ${ }^{27}$ A solução parece encontrar-se na linha do argumento apresentado por 0 elkers, segundo o qual os conteúdos devem ser erigidos através de um processo dialógico sem que tudo se dissolva numa mera formalidade processualística. 0 metodológico não pode assumir completamente as rédeas, conduzindo tudo na direção da dissolução completa no relativismo.

O notável da teoria ética consiste no fato de que ela pode ser formulada de maneiras diferentes, mascada teoria semprenecessita formular pretensões universais de validade. (...) 0 objeto da teoria não pareceser tão plural quanto ela própria, eelenão muda a partir de premissas diferentes. Proposições morais sempreformulam obrigaçõesetranscendem o próprio contexto. (1992, p. 130 e 139) 


\section{A formação da subjetividade capaz de gerenciar conflitos}

0 projeto tradicional da educação moral, cujos traços característicos eram a universalidade, a objetividade e a autoridade foram criticamente superados pelo pluralismo, subjetividade e antiautoritarismo das propostas contemporâneas. As posições clássicas afirmavam uma ontologia quase inocente e se fundamentavam numa imagem de ser humano que de fato só existe como resultado de um longo processo de autoconstrução. M as essa posição tradicional, embora possa ser considerada ultrapassada, colocou um problema que merece ser considerado a pedra de toque de qualquer nova construção: há que enfrentar 0 paradoxo da educação moral, que consiste na tensão entre o permanente e o transitório e não é suficiente afirmar apenas o princípio do auto desenvolvimento da criança.

0 elkers propõe a refundação de uma ética pedagógica com base no desenho de um corpo de problemas em três dimensões: a) a função e o significado da experiência pedagógica para a constituição de uma subjetividade sem lançar mão de uma auto-organização moral, que regride para além da 'verdadeira subjetividade'; b) a fundamentação argumentativa de uma objetividade ética; e c) esboço de um campo objetual de uma ética pedagógica (1992, p. 141 e ss.). Trata-se de um programa que, ao meu ver, abrange os principais elementos da educação moral no contexto plural em que vivemos. Embora os três pontos se condicionem mutuamente, quero limitar meus comentários finais ao conceito de subjetividade, já que este se relaciona mais diretamente à prática educativa, enquanto os dois outros fazem parte da reflexão ética propriamente dita. Entendo que um dos objetivos da educação moral é contribuir para que os educandos constituam, paulatinamente, um núcleo subjetivo a partir do qual possam assumir autonomamente a responsabilidade das decisões que a vida, a cada momento, exige.

Por subjetividade entende-se um mundo interior autônomo e autoorganizado. Esta autonomia não pode ser entendida como um espaço interior isolado das circunstâncias culturais, uma vez que nenhuma identidade pode ser concebida ou construída independentemente dos espaços públicos, nos quais sempre já estão presentes determinados conceitos como igualdade e altruísmo. Estes conceitos estão, desde logo, presentes ao mundo interior e não há subjetividade que não se constitua a partir desses pressupostos. Em outras palavras, a subjetividade constitui-se num determinado mundo cultural. M oral, portanto, encontra-se 
dentro e fora. $N$ esse sentido, as obrigações que nos vêm de fora não são um corpo estranho ao tecido moral da subjetividade. $M$ as como nascem as obrigações? Certamente não como uma imposição vinda de uma subjetividade externa. Elas são o resultado de uma reflexão acerca da plausibilidade e legitimidade de proposições pedagógicas. Relevante do ponto de vista pedagógico e moral é que os princípios sejam assumidos (pelo indivíduo) como obrigação e não aceitos como uma imposição de fora.

A subjetividade não existe isolada como uma mônada, anterior e independente do cosmo sócio-moral que a cerca. Ela tem como suposto necessário a dimensão da intersubjetividade. Podemos admitir que a dimensão intersubjetiva já fazia parte dos modelos tradicionais de formação. N este caso, porém, a relação intersubjetiva esgotava-se na adaptação de cada indivíduo àquilo que estava previamente estabelecido. Subjetividade, no entanto, não é apenas o resultado desse processo de adaptação, mas de autoconstrução. Esta, por sua vez, não é autárquica nem monádica. Subjetividade e subjetividades são mundos de limites porosos que favorecem e estão condicionados pela influência mútua. "A subjetividade existe para si, mas sob a condição de mundos simbólicos e pretensões morais cuja comunicação é inevitável." (0 elkers, 1992, p. 144). A aprendizagem de contextos morais não significa que eles sejam simplesmente internalizados. Trata-se de um processo de elaboração que é estimulado e, em certa medida, condicionado a partir da objetividade dos ambientes morais simbólicos externos, que são formulados pela estrutura interna de cada um. Da confluência destes dois mundos - o objetivo externo e o subjetivo interno - nasce a eventual plausibilidade que constitui o fundamento da obrigação. Esta obrigação não é, portanto, nem uma imposição a partir de fora, nem um desenvolvimento a la Rousseau de uma natureza interna, isolada do exterior. Interior e exterior relacionam-se de forma dialético/ dialógica. A subjetividade não se dissolve no intersubjetivo, mas em nenhum momento ela é de todo independente do contexto externo. A relação com o exterior se dá através de configurações simbólicas, razão pela qual não se trata de uma relação imediata, mecânica entre o interior e 0 exterior. A subjetividade existe para si sem, no entanto, ser monádica ou autárquica. Ela existe no contexto condicionante de mundos simbólicos, cujas pretensões de validade a afetam através da tecitura porosa de sua autonomia. $\mathrm{N}$ a verdade, as pretensões universais de validade só podem ser apreendidas por meio de formulações subjetivas, mas isso significa que mundos morais podem ser aprendi- 
dos. Aprender não é uma aceitação ou internalização incondicional, mas um trabalho formulativo, não conformação, mas conformulação.

Seguindo este raciocínio, poderíamos dizer que a educação moral é a presença pedagógica junto ao educando que tem como objetivo 0 despertar de suas competências morais. Papel central ocupa, na minha opinião, o despertar da consciência dos educandos para os problemas e contradições da sociedade contemporânea e sua forma de organização, tematizando a perspectiva exclusivamente individualista instrumental e recentralizando o interesse do educando sobre a dimensão do social e a responsabilidade que cabe a cada um na sua transformação.

A relação entre educador e educando não é a mesma em todas as idades. Q uanto mais jovem o educando, maior deve ser a presença do educador. As crianças são confrontadas com mundos, cujo conteúdo simbólico e nível de exigência elas precisam aprender não para simplesmente internalizá-los ou adaptar-se a eles, mas para conhecếlos e reconhecêlos como frutos históricos da comunidade e assimilá-los, formulativamente, na medida do seu amadurecimento. Para 0 elkers, esta situação da criança justifica um paternalismo 'fraco'. (1992, p. 145). A criança não é um sujeito moral por natureza, mas ela deve ser inserida num processo como sujeito que, progressivamente, vai conquistando maior autonomia. Por isso, o processo educativo deve ter em conta estas duas dimensões: a subjetiva e a objetiva. A objetiva, que chega ao indivíduo pela formulação simbólica mediada através da linguagem, e a subjetiva, que dispõe de uma autonomia ativa, restrita no início, e ampliada na medida do amadurecimento. $\mathrm{N}$ em a subjetividade se movimenta de forma plenamente autônoma, nem o mundo moral pode ser autoritário e rijamente imposto ao sujeito, mesmo quando este ainda está no início de sua modelação. A subjetividade forma-se na relação dialético/dialógica com os mundos morais. ${ }^{28}$

Porque educação moral deve ser entendida como processo dialético/ dialógico? No processo de aprendizagem, a criança não assimila apenas um conjunto de princípios morais, mas junto com eles também os respectivos anti-princípios, bem como as estratégias para lidar com os conflitos que derivam desses contra-sensos. O s conflitos são persistentes e inevitáveis, podendo ser resolvidos em termos morais apenas no âmbito da consciência, o espaço da responsabilidade moral. $\mathrm{N}$ ão se trata, porém, de permanentes decisões ad hoc. $\mathrm{N}$ a consciência formam-se lealdades que funcionam como comportamentos gerais (costumes) assumidos conscientemente, ao abrigo das quais são tomadas as decisões na grande maioria dos contra-sensos concretos. D esde a infância, a aprendizagem 
da linguagem moral não tem apenas o sentido estratégico da solução de conflitos, mas tem um efeito residual de importância fundamental na constituição do caráter.

Trata-se de um processo muito complexo, conflituoso e sempre precário, no qual se deve reconhecer pelo menos um certo grau de risco, seja no caso em que se busca introduzir a criança num determinado contexto cultural que desfruta do consenso social, seja, sobretudo, no caso de a educação moral querer despertar na criança uma percepção crítica dos códigos morais vigentes. A criança pode sofrer um certo 'dilaceramento' entre os códigos éticos que lhe são transmitidos por certas instituições sociais como, por exemplo, a família ou a I greja, e os que Ihe chegam através de outras instituições como, por exemplo, a escola. "As crianças têm a liberdade de rejeitar certas arbitrariedades, elas também têm a liberdade de assumir atitudes subversivas, mas elas não podem aprender moralidade e construir projetos de vida fora do ambiente simbólico-semântico no qual se forma seu horizonte de compreensão." (O elkers, 1992, p. 152).

A educação moral não pode ser entendida como um processo de intronização numa cultura a partir de uma subjetividade originária, dotada de algumas potencialidades, as quais, então, são linearmente desenvolvidas no contexto da cultura. $\mathrm{H}$ á um sem-número de variáveis contingenciais que pode interferir nesse processo e dar-Ihe uma orientação completamente imprevista. Se olharmos com atenção para as traje tórias de vida das pessoas, entre as quais a nossa própria, facilmente podemos constatar a influência que as constelações contingenciais podem ter sobre os rumos das existências individuais. Isso revela que apenas aparentemente as pessoas vivem, mesmo desde a sua infância, em ambientes morais estáticos e estáveis. D e outra parte, cabe assinalar, como uma razão a mais do caráter conflitual da experiência moral, que as constelações estáveis são fundamentais para a construção do mundo interior, porém a vida não segue a trilha de um telos oculto.

Um outro aspecto a ser assinalado é o fato de que a aprendizagem moral, sobretudo durante os anos mais jovens, não se dá apenas e talvez sequer primordialmente por meio de um procedimento racional/argumentativo, mas por meio da vivência do ambiente moral. Trata-se de uma aprendizagem através da experiência, cuja importância foi enfaticamente destacada por John D ewey. ${ }^{29} 0$ argumento e a experiência (estética) do mundo moral são duas matrizes da aprendizagem moral. Esta é a razão por que é difícil ou mesmo impossível argumentar convincentemente junto ao aluno a favor de determinadas posições morais, se no contexto 
vivido 0 aluno não fizer a experiência estética destas mesmas proposições. Assim, pouco adiantará tentar legitimar junto aos alunos o valor da democracia se os ambientes em que vivem, inclusive a escola, não forem democráticos. Enquanto não for garantida a igualdade de direito para todos é difícil fazer com que a criança entenda que não é melhor para ela buscar apenas a satisfação dos próprios desejos. Este fato, porém, não deve servir de base para a renúncia ao ensino teórico/argumentativo que transcende 0 âmbito do meramente experiencial. Ao contrário, a iniciação do aprendiz pode abrir o espaço para a elaboração crítica do mundo da experiência, favorecendo o desocultamento de seu caráter sorrateiro que condiciona antes mesmo que a pessoa se dê conta disso. Se acreditarmos que comportamentos morais são fruto de uma história da aprendizagem e não resultado de um bloco de verdades impostas, então é importante que a face subjetiva, isto é, argumentativa desta história não esteja em contradição com a experiência estética objetiva.

$\mathrm{N}$ estes termos, 0 ensino da moral parece-me possível e importante ainda que não possa em nenhum momento oferecer garantias de sucesso. D e um lado, a educação moral opera sempre com uma antropologia otimista, num horizonte, portanto, que acredita na possibilidade de que o ser humano e a sociedade possam tornar-se melhores através da contribuição da educação. De outro, a educação tem consciência de que a formação moral não é um processo que tem começo e fim, orientado para objetivos que serão al cançados por meio de procedimentos pedagógicos adequados e controlados. $\mathrm{N}$ ada disso é real na vida humana. Se não podemos partilhar o pessimismo das antropologias negativas que negam a possibilidade do progresso porque estão convencidas de que a natureza humana não pode ser melhorada, também não é possível acreditar num sucesso planejado e seguro. Ainda que a educação seja um processo aberto, cujo desfecho não pode ser previsto em decorrência das inúmeras variáveis subjetivas e objetivas, o horizonte deste processo aberto pode representar uma oportunidade imperdível de engajamento para que a vida dos indivíduos e da sociedade melhore. M elhorar significa caminhar em direção a um ponto futuro em que as relações do homem com a natureza e as relações dos homens entre si sejam tais que permitam a todos o maior grau de felicidade possível.

A diferença entre as concepções tradicionais e as modernas consiste na valorização de processos públicos de fundamentação, o que não implica a negação do caráter geral, universal e vinculante de princípios mínimos que não podem ser tidos como meras convenções. Ao contrário, o espaço público deve ser precisamente 0 ambiente onde tais princí- 
pios mínimos sejam colocados a claro. Os códigos morais podem e devem diferenciar-se, mas disso não segue um pluralismo arbitrário que entende a moral como um assunto restrito aos contextos locais. Q uem nega a possibilidade de desideratos mínimos nega a própria moral e começa a falar de outro assunto. Aqui se descortina o espaço dos grandes temas e sentidos (sociais, políticos, econômicos, antropológicos) que a educação moral deve oferecer aos educandos para que el es se conscientizem da realidade sociocultural na qual vive o homem de hoje. $\mathrm{N}$ ão é possível detalhar aqui a dimensão social da educação moral, que aponta para a consciência e a responsabilidade transformadora que o homem (moral) contemporâneo deve assumir. Q uero deixar claro que esta dimensão é inerente e indispensável para uma educação moral numa sociedade que apresenta um quadro profundamente preocupante de miséria, fome, desigualdade social, agressão ao meio ambiente e desenvolvimento científico-tecnológico ${ }^{30}$ cujas conseqüências causam a marginalização e morte de milhões de pessoas e colocam em risco o futuro da própria espécie humana.

\section{Palavrasfinais}

Evito, propositalmente, a palavra conclusão porque a natureza precária e inacaba do texto que me atrevi a apresentar ao leitor ainda não permite conclusões. Foi minha intenção assinalar algumas questões teóricas que se escondem por detrás do discurso aparentemente sem problemas a respeito da educação moral. Procurei mostrar que, atualmente, nos encontramos em meio a um ambiente de desestabilização dos valores tradicionais, transcendentais e fixos, que eram transmitidos às novas gerações pela educação. Vivemos num mundo plural em que não há mais consensos em torno daquilo que devemos entender por educação moral. Esta desestabilização tem como contrapartida as manifestações cada vez mais recorrentes que constatam a necessidade de um novo incremento da formação moral do indivíduo ante a situação de crise de sentido e dos riscos da sociedade contemporânea. A volta ao passado não é possível. Se um caminho há, este deve ser encontrado a partir do presente, das ambivalências, dos múltiplos sentidos, das contingências. É neste contexto que a educação moral deve acontecer.

A tarefa da educação moral é aprender a lidar com as incertezas. I sso supõe a superação da relação educativa tradicional, caracterizada pela transmissão de certezas aos alunos, e a adoção de uma nova perspectiva reflexivo/comunicativa. Trata-se desensibilizar os alunos para a questão 
da moralidade, introduzi-los no debate dos temas mais importantes que envolvem o ser humano e a sociedade na contemporaneidade, buscando contribuir para a formação de uma subjetividade a partir da qual cada pessoa possa fazer as suas leituras e tomar as suas decisões.

Procurei deixar claro também que, apesar dos recorrentes discursos pós-moderos que se aproximam perigosamente do relativismo moral, tal posição me parece não só teoricamente insustentável, mas politicamente perigosa, pelo menos para aqueles que ainda acreditam num futuro melhor para o indivíduo e a sociedade. Se já não dispomos de verdades fixas e transcendentes que podemos 'ensinar' aos educandos, também não podemos abrir mão de princípios mínimos a respeito dos quais não há como negociar. São princípios como o respeito à dignidade, respeito à vida, ao meio ambiente e a afirmação de uma atitude de solidariedade. Estes princípios mínimos representam o chão seguro e inegociável a partir do qual é possível gerenciar conflitos e admitir espaços para as contingências de um mundo plural.

N uma palavra, educação moral é possível e talvez mais necessária do que nunca. Ela não pode ser mais levada a cabo nos mesmos moldes, como era feito no contexto em que havia consenso a respeito de certas verdades que eram transmitidas de geração em geração.

$\mathrm{H}$ oje, trata-se de entender o processo educativo como constituinte, ele mesmo, da moralidade. 0 educando deve ser visto, portanto, como o sujeito de sua formação moral e não mais como alguém que padece tal formação.

Recebido para publicação em setembro de 2001.

\section{N otas}

1. É notável que os mais representativos filósofos das mais diferentes correntes do pensamento contemporâneo dediquem importante parte de suas obras ao tema da ética. Exemplos são Adolfo Sánchez Vasquez, Etica, M exico: Patrício Sanz, 1969; John Rawls, A theory of justice, $\mathrm{H}$ arvard: $\mathrm{H}$ arvard University Press, 1971; $\mathrm{H}$ ans Jonas, D as Prinzip Verantwortung, Frankfurt: a. M ain, 1984; 0 tfried $\mathrm{H}$ öffe, Strategien der H umanität, Freiburg/M ünchen, Karl Alber Verlag 1975; Jürgen $\mathrm{H}$ abermas, M oralbewustsein und kommunikatives $\mathrm{H}$ andeln, Frankfurt: a. $\mathrm{M}$ ain, Suhrkamp Verlag, 1983; K arl-O tto Apel, Diskurs und Verantwortung, Frankfurt a. M ain, Suhrkamp Verlag, 1990; Ernst Tugenhat, Vorlesungen über ethik, Frankfurt a. M ain, Suhrkamp Verlag, 1993; Jean-François Lyotard, M oralités postmodernes, Paris: Galilée, 1993.

2. E. Tugenhat formula a questão assim: "Como podemos, como devemos nos posicionar em relação à ética, depois que a fundamentação religiosa deixou de existir?" (1997, p. 14).

3. Wittgenstein aparentemente desestabilizou esta tradição a partir de sua teoria dos jogos de linguagem. Cf. Lyotard, 1985, p. 25. 
4. Cf. Walter Reese-Schäfer, Frankfurt a.M .: Suhrkamp Verlag, 1997. N esta obra, Reese e Schäfer analisam as diferenças entre o pensamento ético de três grandes filósofos da contemporaneidade, a saber, Karl $\mathrm{O}$ tto Apel, Jürgen $\mathrm{H}$ abermas e $\mathrm{O}$ tfried $\mathrm{H}$ öffe. A estes autores poderiam ser acrescentados muitos outros (John Rawls, $\mathrm{H}$ ans Jonas, Ernst Tugenhad, entre outros) que tanto se distinguem dos primeiros quanto entre si.

5. Cf. 0 elkers, J., Pädagogische ethik, 1992, p. 8.

6. Além das discussões teóricas, registra-se no contexto da escola a preocupação com os chamados temas transversais, no caso, com a ética, mas também no mundo empresarial, bem como no contexto da C\& T, o tema da ética aparece com grande destaque.

7. Com isso concordam até mesmo pensadores pós-modernos como G. Vattimo: "As dificuldades do pensamento pós-moderno mostram que não se pode deixar vacante sem mais o posto antes ocupado pelos 'metarrelatos' e pela filosofia da história." (1992, p. 35).

8. H á circunstâncias em que a transgressão não só se justifica, mas pode ser uma exigência moral. Se alguém, por não querer mentir, revela o esconderijo da filha ao estuprador, certamente está agindo de forma imoral.

9. Rousseau diz que "há duas espécies de dependência: a das coisas, que é da natureza; a dos homens, que é da sociedade. A dependência das coisas, não tendo nenhuma moralidade, não é nociva à liberdade e não engendra vícios; a dos homens, sendo desordenada, os engendra todos. (...) Conservai a criança tão-somente na dependência das coisas; tereis seguido a ordem da natureza nos processos de sua educação". Rousseau, Emílio ou D a Educação, 1992, p. 68 e 69.

10. Rousseau, 1992, p. 68.

11. Platão, A República (Livro VII), 1987.

12. Alguns autores, chamados pós-modernos, defendem a posição de que a humanidade entrou ou está entrando numa fase que se pode chamar de pós-moral. Ver Lipovetsky, 0 C repúsculo do dever - A ética indolor dos novos tempos democráticos, Lisboa: D. Q uixote, 1994.

13. Esta é a razão da enorme desorientação sentida por aqueles, professores ou pais, que têm o compromisso de dar educação moral às crianças e jovens.

14. N ietzsche escreveu duas obras importantes sobre ética: Para a genealogia da moral e Para além do bem e do mal. N estas obras, o filósofo argumenta duramente contra uma ética tradicional cristã que ele considera uma ética servil, ética do ressentimento, como ele diz, a qual nega os valores positivos da vida.

15. Goergen, P. Pósmodernidade, ética e educação. N este texto exponho com maior detalhe minha posição a respeito da questão da ética no interior do debate entremodernidadee pós-modernidade.

16. M. de A. O liveira comenta que "a reviravolta na reflexão ética efetivada na filosofia kantiana consistiu, em primeiro lugar, na articulação clara da distinção entre normas e princípios. N este caso, a tarefa específica da ciência do ético consiste no 'estabelecimento de princípios', ou seja do 'princípio fundamento' a partir do qual se pode decidir o caráter normativo, obrigante, das normas gestadas historicamente." (1993, p. 148).

17. J. Habermas nos oferece uma interessante posição intermediária entre 0 absolutismo e 0 relativismo histórico. Afirmando a historicidade dos valores, ele afirma que eles adquirem um status de semi-transcendentalidade no contexto da pragmática universal da história da espécie humana. N ormas, regras e princípios surgem na história da pragmática universal a partir de um processo dialógico, no qual se impõe o melhor argumento. A respeito das posições de Lyotard e H abermas sobre esta temática, ver Vattimo, 1992, p. 17.

18. G. Vattimo, por exemplo, entende que "com o triunfo do desencanto, (...) que caracteriza a modernidade, também a relação entre teoria e práxis experimentou um processo de transformação que está em relação com a erosão tanto da própria noção de 'projeto' teórico quanto da noção de fundamentação." (1992, p. 185). 
19. A esse respeito, ver $\mathrm{H}$ eidegger, $\mathrm{M}$., Sobre a essência do fundamento, Coleção Os Pensadores, 1989, e Conferências e Escritos filosóficos. Trad. de Ernildo Stein, São Paulo: N ova Cultural, p. 83-115.

20. O pensamento dito pós-moderno radica na filosofia de $\mathrm{N}$ ietzsche (1844-1900) e H eidegger (1889-1945).

21. Ver texto de Jörg Zirfas neste número de Educação \& Sociedade.

22. Desde este ponto de vista, parece que a educação moral torna-se cada vez mais questionável, porque desprovida de fundamentos que a legitimem. M uitos defendem, então, uma educação meramente instrumental, voltada para a geração de recursos racionais e técnicos que permitam ao educando, tão logo deixe a escola, inserir-se no mercado. É a vitória de uma proposta educacional em que o ter e não o ser torna-se o objetivo dominante. Trata-se de um modelo de escola definida por K. Schaller como "escola de resultados e da ciência" (Schäfer/Schaller, 1973, p. 77).

23. Refiro-me à escola de modo geral e não apenas à disciplina correspondente ao tema transversal da ética.

24. Na expressão de $\mathrm{H}$ abermas, o espaço público representa "o recurso reflexivo àquilo que Kant havia fixado na imagem das operações constitutivas do sujeito, ou, como dizemos hoje, a reconstrução de pressupostos universais e necessários sob os quais os sujeitos capazes de falar e agir se entendem mutuamente sobre algo no mundo." (1989, p. 145). Acrescente-se que H abermas toma uma posição decidida contra o relativismo moral: "A ética do discurso contesta a suposição básica do relativismo ético, segundo o qual a validez dos juízos morais só se mede pelos padrões de racionalidade ou de valor da cultura ou forma de vida à qual pertença em cada caso o sujeito que julga." (1989, p. 147-148).

25. Se, de um lado, somos obrigados a reconhecer que particularmente a mídia exerce crescente influência educativa sobre as pessoas, de outro, não podemos facilmente admitir que ela se equipara à educação formal. Há diferenças importantes que não devem ser esquecidas. Em primeiro lugar, devemos lembrar que a educação escolar é um processo no qual os gestos educativos são sistematicamente organizados e permanentemente tematizados na sua dimensão metodológica e de conteúdo na busca de legitimação.

26. Considero que seria da mais alta relevância social que a mídia se conscientizasse de sua responsabilidade educativa e moral, participando do debate público acerca dos princípios morais mínimos a serem respeitados no interesse do ser humano e da comunidade.

27. N este sentido, a posição pós-moderna de Lyotard, que para definir o estatuto da moralidade se serve do termo wittgensteiniano dos jogos de linguagem, é antes um ponto de partida estético do que ético. Cf. Lyotard, 1985, p. 25.

28. A respeito de como acontece o processo de autoconstrução da subjetividade em termos da relação psicofísica, ver o texto de E. M orin, "A noção de sujeito", In: Friedmann, D. N ovos paradigmas, cultura e subjetividade, Porto Alegre: Artes M édicas, 1976, p. 45-58.

29. Cf. D ewey, Experiência e educação, São Paulo: Editora N acional, 1976, e Vida e educação, São Paulo: Edições M elhoramentos, 1973.

30. Nas palavras de G. I ben, "sem dúvida há entrementes um amplo consenso a respeito de que ante a ameaça da catástrofe climática, o aumento da fome, da guerra, da violência e da pobreza e da incrível desigualdade na distribuição de riquezas, não podemos mais continuar como até agora: 'depois de nós o dilúvio'".

\section{Moral education: Training or communicative RefLection?}

ABST RACT: T histext seeks to elucidate some of themost relevant aspects of moral education in the context of our contemporaneous, plural world. It 
assumes that moral education is possible and necessary, even in the current setting wherethe fixed, universal values of tradition are destabilized. Such moral education, which can no longer be considered as the transmission of moral values and behaviors, consists of the introduction of learnersinto the conflicting world of moral conceptions, aiming at minimum consensuses that lay thebasesfor their moral actions. Through a reflexive communicative pedagogical relationship one hopes to heighten the students awareness of the morali ty problems, as well as structure a subjectivity that allows anyone to responsibly make their own moral decisions.

Key words: M oral education; Ethics; Values, Subjectivity; Plurality.

\section{Referências bibliográficas}

BEN N ER, D. H auptströmungen der erziehungswissenschaft. M ünchen: Paul List Verlag, 1973.

BEUT LER, K. \& H O RSTER, D . (O rgs.). Pädagogik und ethik. Stuttgart: Philipp Reclam, 1996.

CULLEN , C. Autonomia moral, participación democrática y cuidado del outro. Buenos Aires/M exico: N ovedades Educativas, 1999.

DILTHEY, W. Pädagogik, geschichte und grundlinien des systems, Gesammelte Schriften, Band IX, Stuttgart: Teubner Verlagsgesellschaft, 1974.

FREIRE, P. Pedagogia do oprimido. Rio de Janeiro: Paz \& Terra, 1975.

GARZ, D. M oral, erziehung und gesellschaft Bad H eilbrunn/O bb. Klinkhardt, 1998.

GIDDENS, A. "Structuralism, pos-structuralism and the production of culture". In: GIDDENS, Anthony, Social theory and modern sociology. Cambridge/O xford: Polity Press, 1987, p. 73-108.

GOERGEN, P. Pós-modernidade, ética e educação. Campinas: Autores Associados, 2001.

HABERMAS, J. Consciência moral e agir comunicativo. Rio de Janeiro: Tempo Brasileiro, 1989.

$\mathrm{HÖ} F F E, O$. Kategorische rechtsprinzipein. Ein kontrapunkt der moderne. Frankfurt a. M .: Suhrkamp Verlag, 1990.

IBEN, G. Demokratie und ethik wohin? M ünster: Lit Verlag, 1997. 
KANT, I. Ü ber pädagogik. Bochum: Ferdinand Kamp Verlag, s/d.

KOH LBERG. L. The philosophy of moral development: M oral stages and the idea of justice. San Francisco, 1981.

LYOTARD, J.-F. A condição pós-moderna. Lisboa: Gradiva Publicações, 1985.

M oralidades pós-modernas. Campinas: Papirus, 1996.

NIETZSCHE, F. Jenseits von gut und böse, vorspiel einer philosophie der zukunft, M ünchen: Wilhelm Goldmann Verlag, s/d. $\mathrm{s} / \mathrm{d}$.

Zur genealogie der moral. M ünchen: W ilhelm Goldmann Verlag,

OELKERS, J. Pädagogische ethik. Weinheim und M ünchen: Juventa Verlag, 1992.

O LIVEIRA, M. A. de. Ética e sociabilidade. São Paulo: Edições Loyola, 1993.

Ética e práxis histórica. São Paulo: Ática, 1995.

PLATÃo. A República (Livro VII). Lisboa: Fundação Calouste Gulbenkian, 1987.

RATT NER, J. Grosse pädagogen. M ünchen/Basel: Ernst Reinhardt Verlag, 1968.

RO USSEAU , J.J. Emílio ou Da Educação. Rio de Janeiro: Bertrand Brasil, 1992.

REESE-SCH ÄFER, W. Grenzgötter der moral. Frankfurt a. M .: Suhrkamp Verlag, 1997.

SCH ÄFER/SCH ALLER. Kritische erziehungswissenschaft und kommunikative didaktik. Heidelberg: Q uelle und M eyer, 1973.

TU GEN H AT, R. Lições sobre ética. Petrópolis: Vozes, 1997.

VATTIM O, G. Ética de la interpretación. Buenos Aires: Editorial Paidós, 1992. 